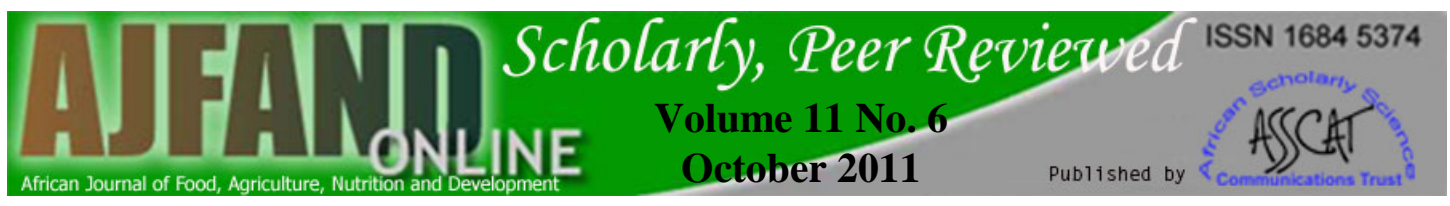

\title{
SIZE REDUCTIONOF FOOD COMMODITIES AND FOOD SAFETY IN SOME ACCRA MARKETS
}

\section{Sinayobye $\mathbf{E}^{1 *}$ and FK Saalia ${ }^{2}$}

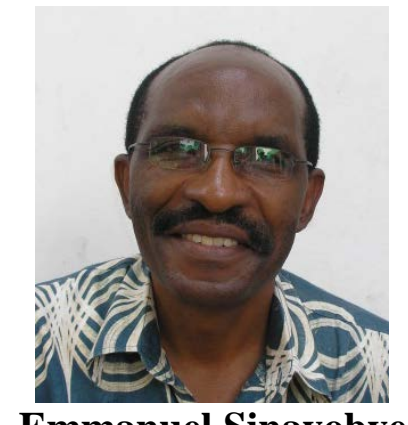

Emmanuel Sinayobye

*Corresponding author email: esinay@ug.edu.gh

${ }^{1}$ Department of Food Process Engineering,University of Ghana, Legon. Accra, Ghana.

${ }^{2}$ Department of Food Science and Nutrition, University of Ghana, Legon. Accra, Ghana. 


\section{ABSTRACT}

The objective of this paper is to investigate the food safety and hygienic status after size reduction in some Accra markets, using questionnaire and bacterial samples to validate the questionnaire findings. The primary research was done in the Kaneshie, Makola and Nima markets in Accra. The work involved more than 55 milling machines in these different and affluent markets. The audit form used consisted of a number of questions for each of the 21 respondents chosen at random with a range of one to three machines, some owning up to 5 machines. In addition to the audit,36 samples of tomatoes were taken before and after milling to assess their microbiological safety and the microbial total load by evaluating the platecount agar (PCA), and Violet Red Bile Glucose (VRBG) for the detection and enumeration of Enterobacteriaceae such as Escherichia coli indicating the presence of potential faecal contamination. All 36 samples from the three markets were relatively microbiologically contaminated. The contamination load increased with the milling time. After size reduction of the foods they came out of the machine more contaminated than they entered. Some foods are subjected to adulteration in the size reduction machine. The results of this study suggest that even though most of the foods are cooked before consumption it is necessary to put in place good manufacturing practice (GMP) which must be followed starting with Hazard Analysis and Critical Control Points (HACCP) principles. If this is not done, consumption of such products could lead to serious health hazards especially where they are not cooked enough to eliminate the microbial loads. Disinfection of the machine and the environment will be necessary after each milling session. The products to be milled should be of better microbial quality as well so that the milled product can be safe for consumption. The enforcing agencies and other stakeholders also have a big role to play in terms of awareness and education for the good of the consumer.

Key words: Size reduction, food safety, HACCP, GMP

List of abbreviations

\begin{tabular}{|l|l|}
\hline AMA & Accra Metropolitan Assembly \\
\hline GMP & Good Manufacture Practice \\
\hline HACCP & Hazard Analysis and Critical Control Points \\
\hline PCA & Plate Count Agar \\
\hline VRBG & Violet Red Bile Glucose \\
\hline
\end{tabular}




\section{INTRODUCTION}

The Ghanaian population has increased about five times compared to the population at Independence. As a result there is an increase in the demand for food to feed the population. This has made it necessary to mechanize food production and processing to increase the shelf life of the food commodities and also help feed the increasing population.

Size reduction is an important unit operation in local Ghanaian traditional food processing. Root crops, cereals, and vegetables and many other foods are popular in the Ghanaian food delivery system. These produce undergo processing operations in which they may undergo some form of size reduction.

Size reduction may improve the extraction of a desired constituent from a composite structure. For example, flour may be obtained from wheat grains, juice from sugar cane or paste from tomatoes through size reduction.

Reduction to a definite size range may be a specific product requirement for some processes.

A decrease in particle size of a material leads to an increase in surface area of the solid. This increase in surface area reduces the rate of execution of some processes as indicated below:

- The drying time for moist solids is reduced considerably by increasing the surface area of the solid.

- The rate of extraction of a desired solute is increased by increasing the contact area between the solid and the solvent.

- Process time required for certain operations such as cooking, blanching can be reduced by cutting, shredding or dicing the process material before the operation.

Intimate mixing or blending is usually easier with small size ranges of particles.

In the Ghanaian markets the most popular size reduction used is based on the principle of attrition using a disc attrition mill [1]. They use attrition or shear forces because fine grinding is preferred by customers maybe for all or part of the reasons enumerated above.

Generally, the mills are privately owned and operated mostly in public places such as the food markets. At these places, most millers would generally not discriminate among commodities, but would rather go ahead and mill just about every type of food commodity, provided the machine can withstand the pressure or load put on it. As a result of this attitude, cross contamination and adulteration of commodities may also occur regularly mainly because cleaning procedures in-between products are usually inadequate or inexistent [2, 3, 4]. Cross contamination or adulteration of products may 
affect food quality attributes like color, flavor, and functionality that can harm consumers.

On the other hand, due to the design of the shape of the machine and inadequate cleaning of the machine, microbial loads may increase and cause microbial food contamination or food poisoning.

Food safety is defined as an assurance that food will not cause harm to consumers when it is prepared and/or eaten according to its intended use [5,6].

A formal programme for promoting and maintaining food safety is essential and the Hazard Analysis and Critical Control Points (HACCP) programme is an ideal, proactive approach to ensure food safety [5, 7]. The HACCP is defined as a management system ensuring products which are microbiologically, chemically and physically safe $[5,8,9]$.

The objective of this study is to survey mill operations in different markets inAccra and determine the food safety of the foods milled and quality awareness of the different mill operators.

\section{MATERIALS AND METHODOLOGY}

Questionnaires were used for the study. The questionnaires were pre-tested at the Madina market in Accra. The operators were also interviewed. From the understanding and response of the questionnaires by the operators and the result of the interviews, the questions were modified in order to obtain reliable responses when used for the study.

Operators were randomly sampled from Madina, Makola, Nima, Novotel, Tudu, Kantamanto and Agbogbloshie markets which are the major markets in Accra. The questions were administered to the operators in Makola, Kantamanto and Agbogbloshie markets. Samples of tomatoes were taken from operators in Madina, Makola and Nimabefore and after milling in order to determine the microbiological loads.

Samples of maize, tomatoes, fish and pepper were also taken after milling to determine the presence of heavy metals.

\section{Microbiological Load Determination:}

Microbial data was generated through sampling of tomatoes before and after milling. Three whole tomato samples before milling and three milled tomatoes samples after were taken at Madina, Makola and Nima markets, making 18 samples in total. Each sample weighed $25 \mathrm{~g}$. They were placed in a sterile plastic container waiting for culturing and measuring of total aerobic plate counts using PCA and coliforms using VRBG. The tomato was ground through a sterile lab grinding machine. 
Ten grams of each food sample were weighed and diluted in $90 \mathrm{ml}$ of peptone water. Subsequent 10 -fold dilutions were made to $10^{-6}$ and $10^{-7}$ for total aerobic microbial load by plate countagar (PCA) and Violet Red Bile Glucose (VRBG) for the detection and enumeration of Enterobacteriaceae such as Escherichia coli indicating the presence of potential faecal contamination [10].

\section{Heavy Metal determination}

The analysis of heavy metals in the milled food was conducted using the digestion standard method with sulfuric acid $\left(\mathrm{H}_{2} \mathrm{SO}_{4}\right)$ and Hydrogen dioxide $\left(\mathrm{H}_{2} \mathrm{O}_{2}\right)$. The determination of the heavy metals was done by atomic absoption spectrophotometer Elmer AAS 400.

After completion, the different questionnaires were coded and the details analyzed, using the data analysis software program SPSS 16.0. From these analyses, it was determined that most of the information gathered were important in making very concrete and conclusive decisions as to how well the operators and the people who patronize their work understood what they did and the machines they used and how their actions affected their health and those of the people who patronize them.

The information gathered also gave us an idea as to where they got their machines from and their knowledge on how to use and maintain them as well.

\section{RESULTS}

The respondents were drawn from five different markets, with 1 respondent each from Tudu and Novotel markets, seven from the Makola market (Tudu, Novotel and Makola which are located close to each other and great Makola are put together under the same name Makola), four from the Kantamanto market, and eight from the Agbogbloshie market (see figure 1). From the results gathered from the bio-data of the respondents, it was realized that, most of the operators were fairly young, with more than $60 \%$ being below the age of 30 and more than $90 \%$ aged 40 or below compared to the range 41 to 60 (see figure 1 ). 


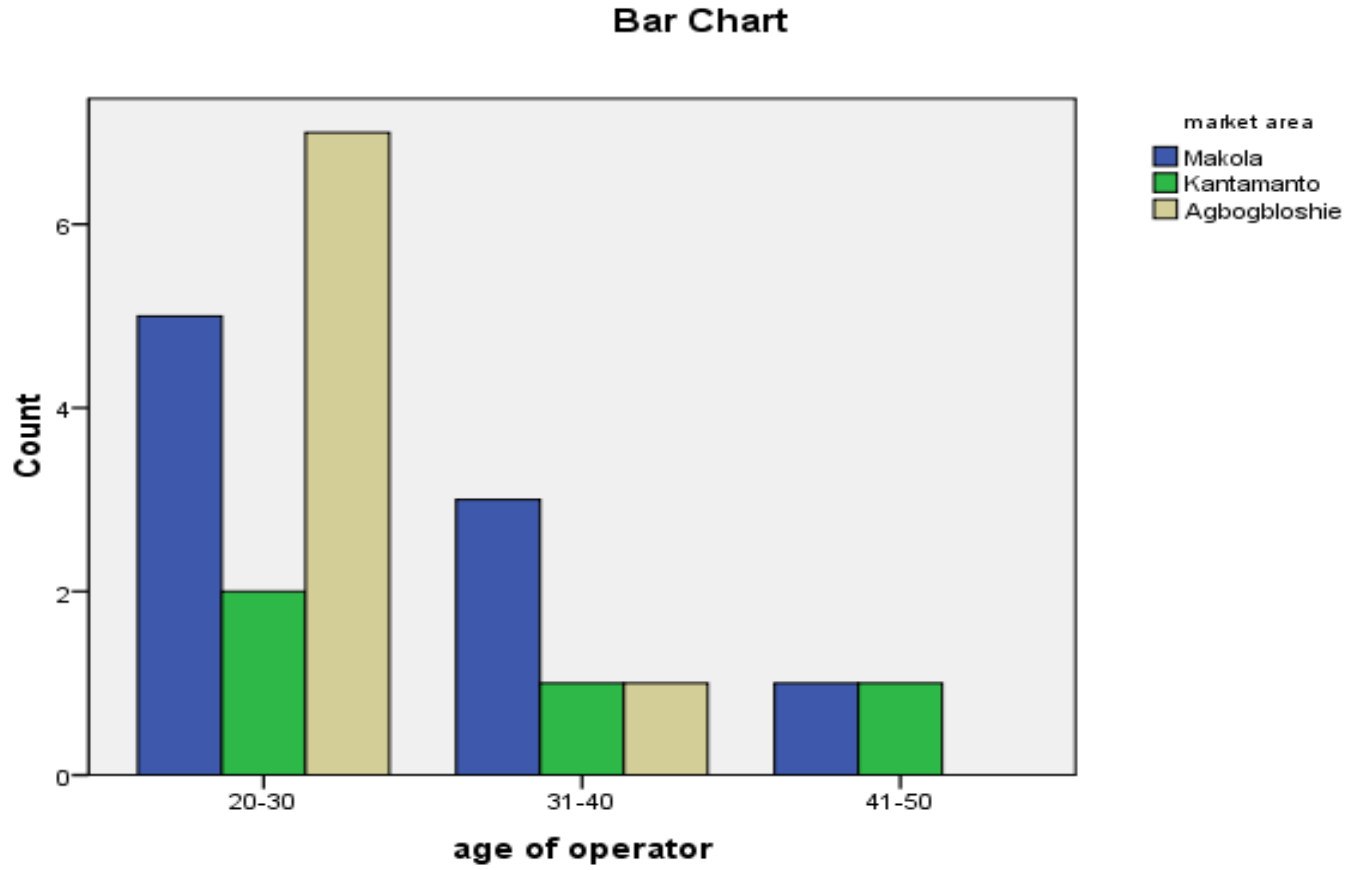

Figure 1: age of operators in different markets

The reason for this trend is that milling of farm produce is in high demand and that bracket of the population needs to cater for themselves and their families so they engage themselves in the milling business.

Besides the milling machines are generally located inside the markets in small rooms with inadequate aeration. The settled dust in the milling room was found most of the time to be beyond the threshold of explosion of $30 \mathrm{mg} / \mathrm{l}$ provided there is a spark (results to be published in a later paper) [1].

\section{Marital Status}

Out of the 21 respondents 13(about 60\%)had already started families and were having marital responsibilities. The married people have been in the work longer than the unmarried because they do not want to move to disorganize their families. The average time spent on the job for married operators is 11years (with a maximum of 27 for someone who is 50 at the time of the study).The average time for the unmarried is 4.8 years. The youngest in the job is single and has spent only 4 months on the job. The young people are more adventurous in trying other and new things.

Most of the married people own the machines so they work with them instead of changing jobs or hiring other people. In case they own more than one machine they hire young recruits under their supervision.

There are more than $66 \%$ married operators in Makola whereas they are almost equally distributed in Kantamanto and Agbogbloshie (see table 1). 


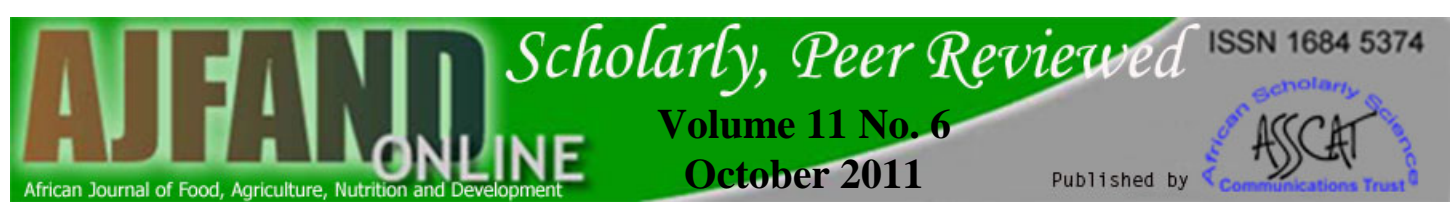

\section{Education}

Twenty four percent of the operators were not formerly educated and more than $95 \%$ of them were male.

More than $66 \%$ of the respondents have junior secondary school education or below. None of the respondents had a tertiary education.

This is so because a highly educated person will normally get a better paying job in a neater environment. Most people went into the business because they could not continue their education because of financial constraints or because they were not good academically. So they found this as a good alternative (see figure 2).

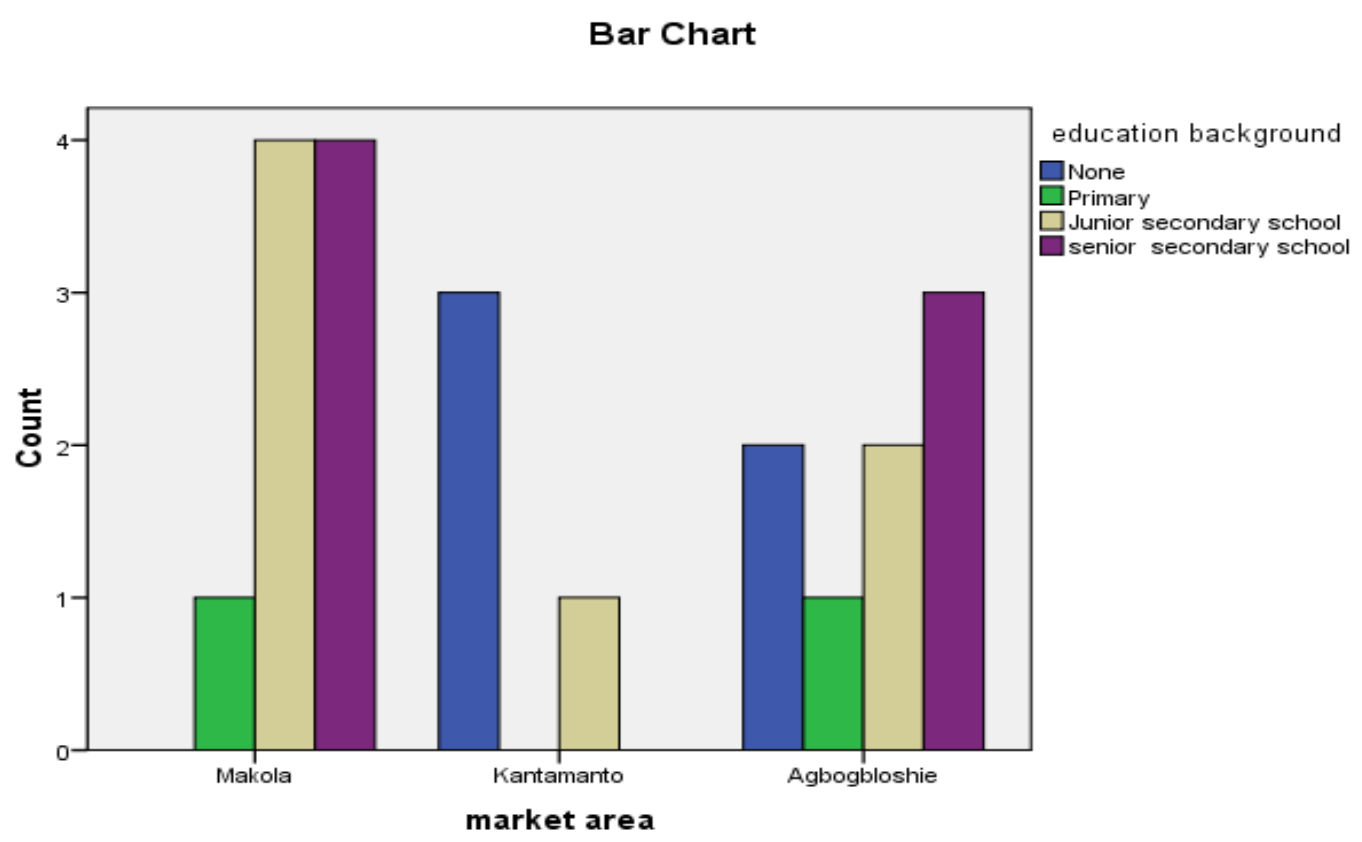

Figure 2: Education background of operators in different markets Milling as a Part-time occupation

On the whole, milling was not the only job done by close to $57 \%$ of the respondents. About $43 \%$ of them engaged in the milling as their main source of income (see figure 3). 


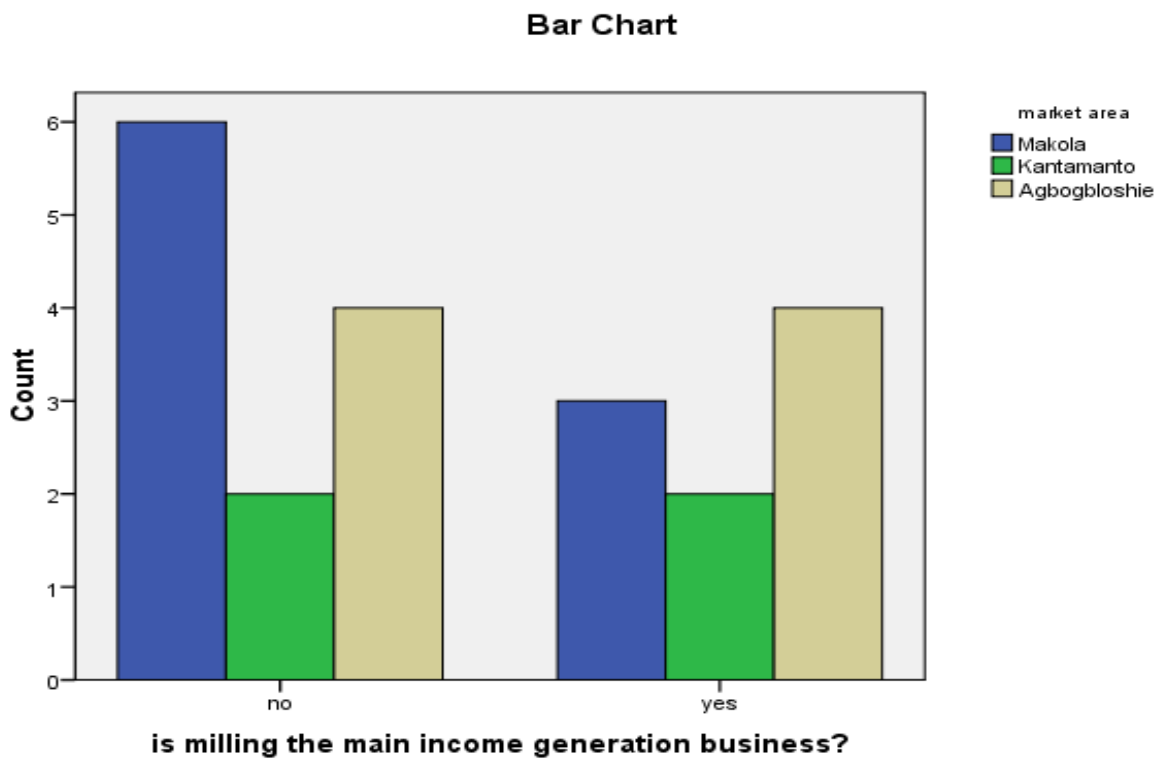

Figure 3: Milling as only income generation business in different markets

Of the percentage that did not rely on milling for their entire income, about $23 \%$ engaged in other businesses like petty trading, welding, and sharpening of knives and other such income generation ventures. The rest were engaged in various occupations such as auto mechanic, driver, computer accessories dealer, sewing and footballer.

More operators at Makola (50\%) said that milling is not their main income generation business compared to Kantamanto and Agbogbloshie where the remaining $50 \%$ were 17 and 33\% respectively. The reason being that Makola is the centre of town and the oldest market so there is likely to be more grinding work there than in the other markets.

\section{Milling machine model and throughput}

Looking at the information gathered with regards to the equipment, operations and maintenance, about $81 \%$ of the respondents could not even tell the name or model of the milling machines used (see figure 4). On further questioning it was found that even out of the 4 who indicated that they know none of them knew exactly. Besides, all of them did not have a clear idea as to the estimated through puts of the machines they were using. If they know they will know also the characteristics of machines used for grinding and they may maintain high quality of final product. 


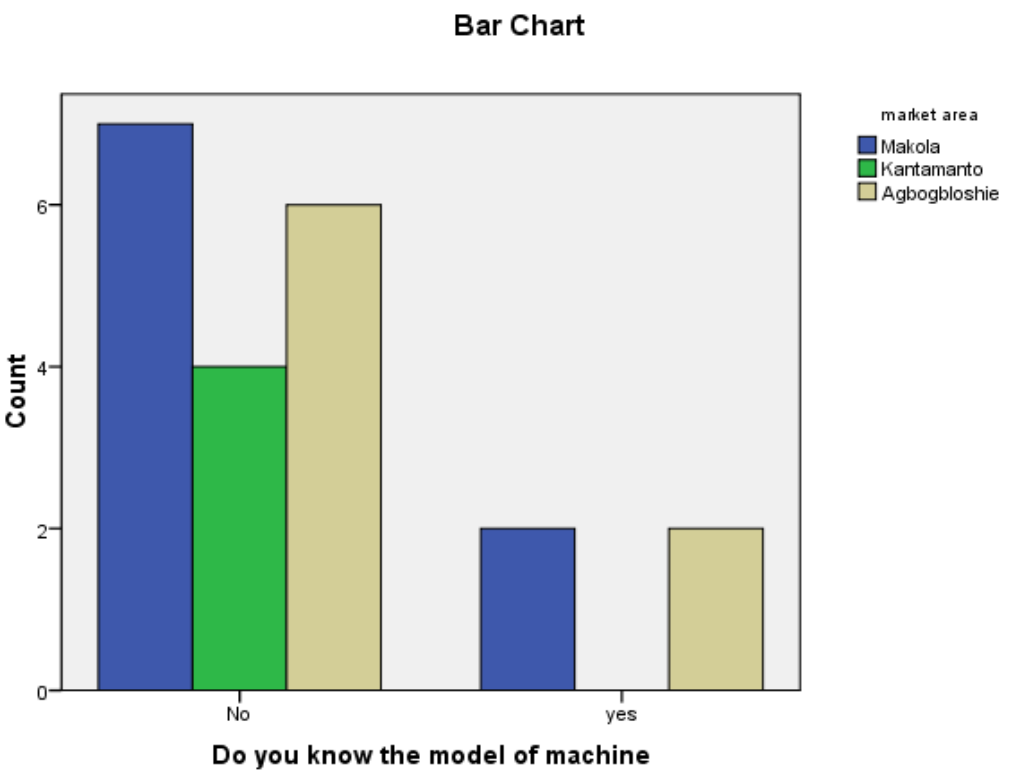

Figure 4: knowledge of the machine by the operator

Thirteen out of the 21 respondents bought their machines locally, 5 bought from importers and 3 moulded them themselves using metals acquired from scrap metal sellers. This shows that they may not know the correct metals to use in fabrication, thus posing a serious threat to their health and those of their customers especially concerning heavy metal incorporation into foods. This together with the fore information that many of the respondents actually had no or very little formal education becomes relevant for serious considerations. Their inadequate educational backgrounds could be a contributory factor to the frequent machine breakdowns. More than $57 \%$ of the respondents indicated that their machines were not robust enough and broke down easily with the remaining(less than 43\%) indicating they got occasional break downs too.

\section{Earning per week in Ghana Cedis*(GHథ)}

(*: 1USD was equivalent to $1.44 \mathrm{GH} \mathbb{4}$ when the study was conducted)

Close to $30 \%$ of the respondents indicated average weekly earnings of GH\$100 and above. The rest earn below that, and out of the remaining percentage, about $47 \%$ of them earned GH\$50 per week.

From the results gathered, it was evident that the cost of milling was generally commodity dependent even though arbitrarily, in most cases, it was left to the judgment of the operator. About $62 \%$ of the respondents said the minimum amount of money they charge for a commodity to be milled was GHpesewa*50 per kilogram or above and less than $40 \%$ charged monies ranging from GHpesewa10 to 30 .

(*: $1 \mathrm{GH}$ is equivalent to $100 \mathrm{GH}$ pesewa) 


\section{Heavy Metals in end-products}

A number of samples contained heavy metals, and the more worrying being the presence of $\operatorname{Lead}(\mathrm{Pb})$ in all the foods sampled in all the markets. Copper $(\mathrm{Cu})$ and Chromium(Cr) were not detected in the samples analysed.

For $\mathrm{Pb}$ the maximum concentration is $0.025 \mathrm{mg}$ per $\mathrm{kg}$ body and $0.3 \mathrm{mg} / \mathrm{kg}$ of food sample according to Codex (CODEX GENERAL STANDARD FOR CONTAMINANTS AND TOXINS IN FOOD AND FEED: Codex Standard 1931995, pdf document). As it can be seen below in table 3, the concentration of Lead is at its maximum acceptable value in all milled foods in Accra markets.

Since more than $90 \%$ are young operators it can be imagined that they will be in the business for the near future. The study showed that most of them were less than 40 it can be imagined that some will spend even more than 20 years until they retire this because most of them own the machines. The habits they have acquired are here to stay as well unless they undergo training/ capacity building.

The number of people who took commodities for daily milling varied considerably. From the data, more than 50 people could visit one operator on the average in a day. If 20 minutes is reasonably the average time required to mill a particular commodity, this gives us an idea as to the kind of pressure the operator dealt with in a day. It also shows indeed that there is no time left for them to clean their machines in between customers. Looking at the variety of mills used, the study indicated that the different milling machines used were actually from various and different sources. Some were imported and others were locally manufactured. Milling machines assembled or molded by the operators themselves were made using locally acquired scrap metals. All the machines had their milling discs molded from scrap metals acquired locally. On the average, most operators spent about GH\$ 5, per week, mostly for maintenance and fixing of faults. In a few cases, some spent between GH\& 15 toGH\& 20 on some days, especially when major faults occurred.

Since there were operators who molded their machines themselves using metals acquired from scrap metal sellers this tells us that they may not know the correct metals to use in fabrication, thus posing a serious threat to their health and that of their customers especially concerning heavy metal incorporation into foods. This is rather a threat to consumers in the near future and for the long term especially because many of the respondents actually had no or very little education. Also, considering the unstable nature of their machines, their educational backgrounds could be a contributory factor to the frequent machine breakdowns.

A wide variety of food commodities are taken to these mill operators per day. Common items usually milled included the following: tomatoes, fresh and dry pepper, onions, ginger, mixed spices, kenkey, dry fish, cassava, palm kernel, beans, groundnuts, traditional medicines, fruits, shrimps, salt, kokonte, tiger nuts, agushi, garden eggs, and millets. Out of these, the survey indicated that one operator may mill more than five different commodities for more than 50 people in a day.

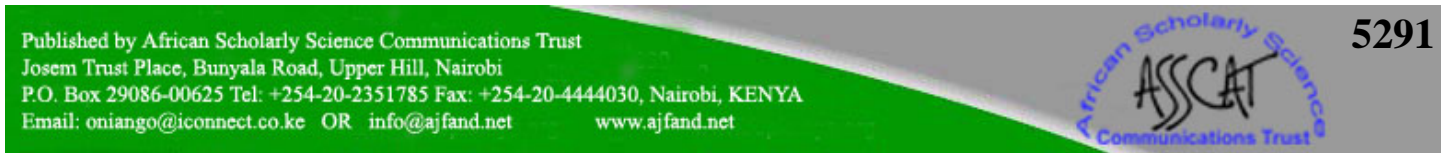




\section{Problem of cross contamination and adulteration:}

Most of the machine operators do not have water in their premises. From the study more than $86 \%$ indicated that they did not have running water of their own in the premises. As they manipulate the machine and the foods before, during and after milling it is evident that their contaminated hands will contaminate the processed foods. Germs will be transmitted from unclean hands after the operator has sneezed, blown his/her nose or wiped his/her eyes or even worse after using the toilet. The study found that most of the operators do not wash their hands or do not use soap and/or disinfectant in their operations. The germs could as well come from the shaking of hands that have been contaminated through handling of contaminated foods from the environment, from petting animals or touching any surfaces they come into contact with.

Operators are not the only culprits because the raw foods are brought in by various customers who could have contaminated them through the same ways described above for the operators.

Food contamination is real and cross contamination frequent.

From these results size reduction of any sample from any market increases the microbial load whether in total counts or in E. coli counts (see table 2, figures 5 and 6). The only exception is with the sample A from Nima market in E. coli and it is believed that that was due to the fact that the un-ground tomato was overloaded and was diluted with less loaded ones as it was being ground. Otherwise the count should at least remain the same after the commodity is ground.

All the samples brought for size reduction were contaminated as well (see table 2) due to the environment they are exposed to. 

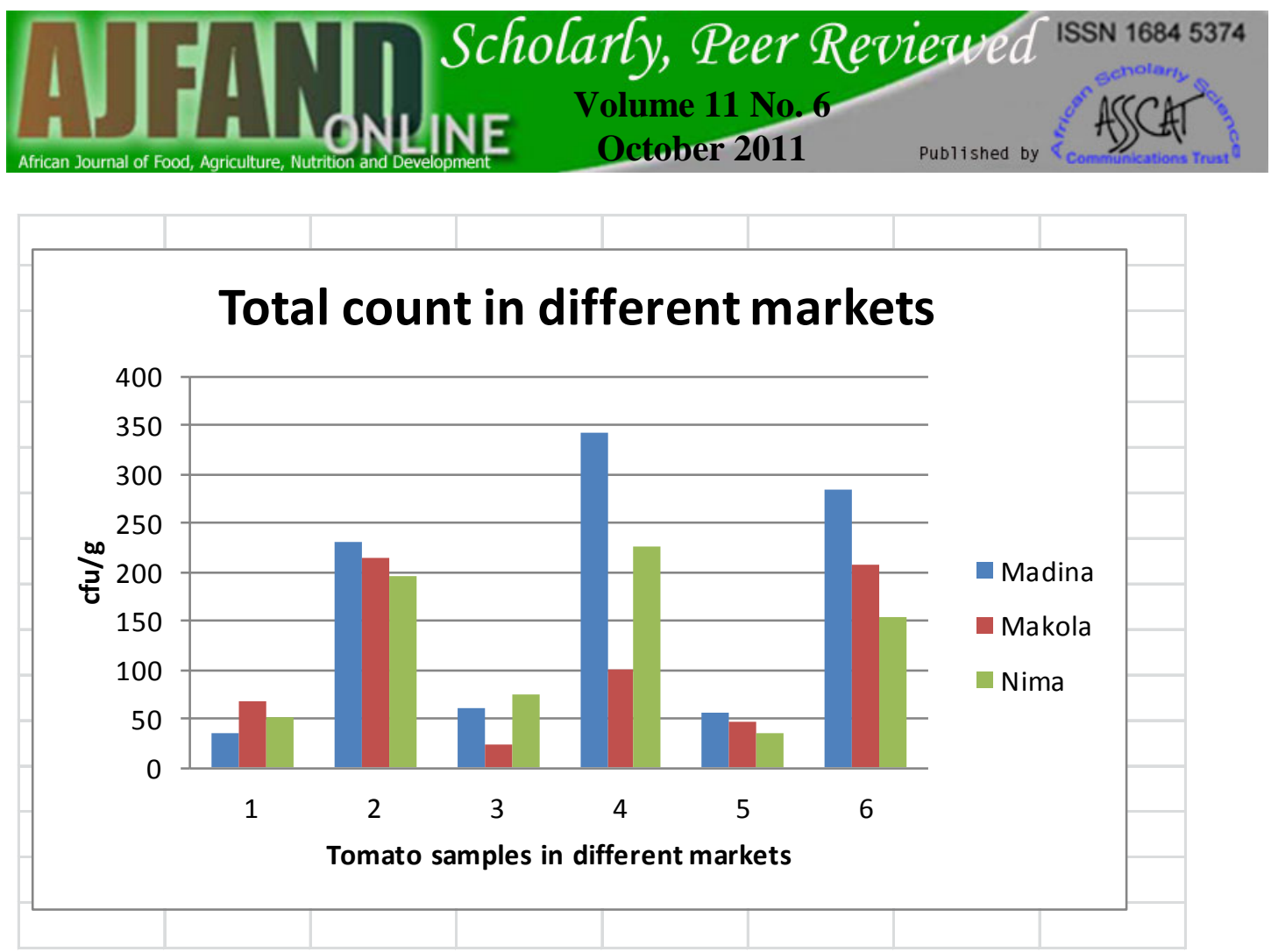

Figure 5: PCA-total counts in the three markets for three samples of tomatoes

1. Sample A of tomatoes before milling in the three markets

2. Sample A of tomatoes after milling in the three markets

3. Sample B of tomatoes before milling in the three markets

4. Sample B of tomatoes after milling in the three markets

5. Sample $\mathrm{C}$ of tomatoes before milling in the three markets

6. Sample $\mathrm{C}$ of tomatoes after milling in the three markets 


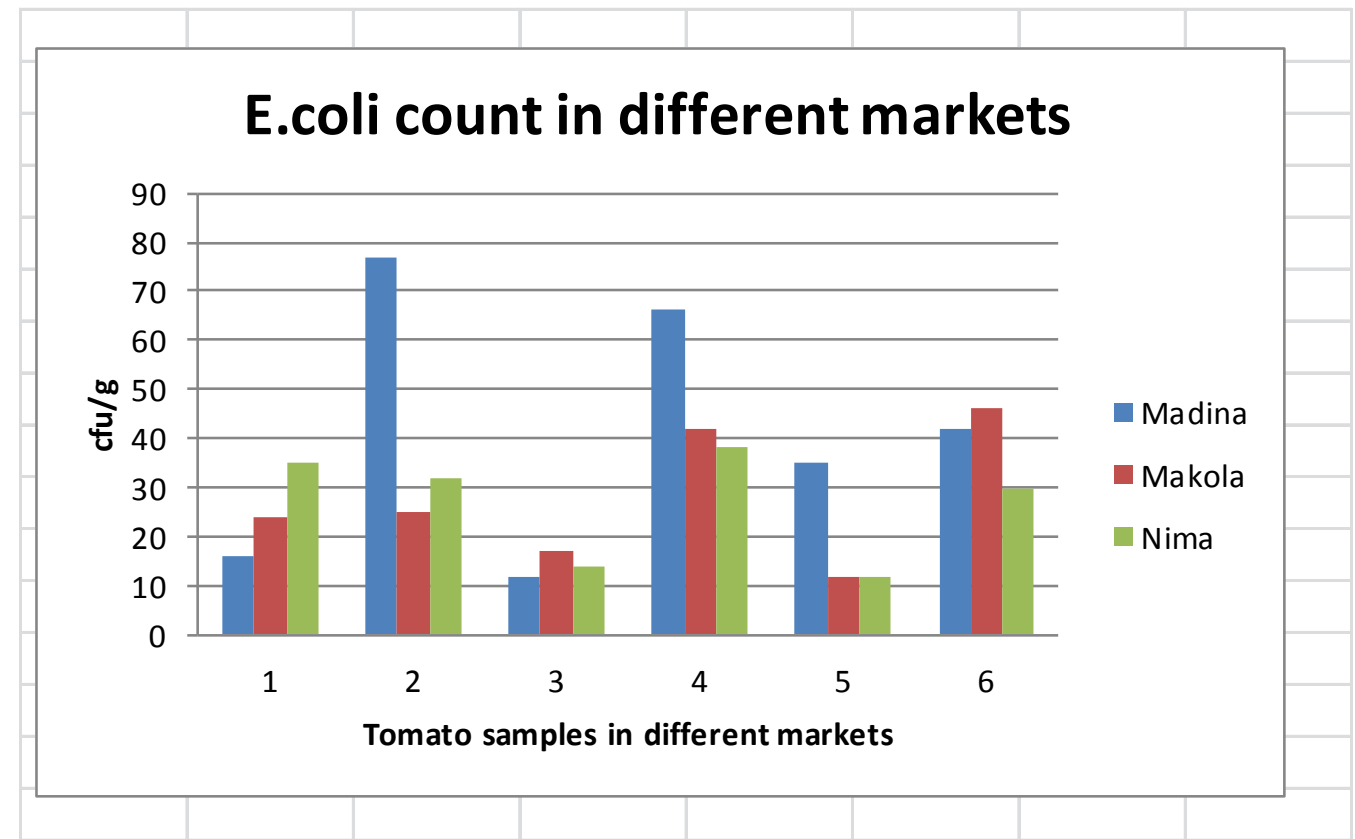

Figure 6: VRBG-E.coli counts in the three markets for three samples of tomatoes 1.Sample A of tomatoes before milling in the three markets

2. Sample A of tomatoes after milling in the three markets

3. Sample B of tomatoes before milling in the three markets

4. Sample B of tomatoes after milling in the three markets

5. Sample $\mathrm{C}$ of tomatoes before milling in the three markets

6. Sample $\mathrm{C}$ of tomatoes after milling in the three markets

\section{DISCUSSION}

Since one operator can have up to 50 customers per day each having an average food commodity of $10 \mathrm{~kg}$ it means that each machine handles $500 \mathrm{~kg}$ a day. Considering 200 milling machines in Accra (which is probably less than the reality!) it leads to 100 tons per day of food milled in Accra. This constitutes an industry on its own which affects a great number of people in one way or another.

The results of the study confirmed the fact that size reduction leads to more contamination of milled foods and most of them even undergo adulteration in the markets.

The results of the study confirmed the fact that the selection of food items for size reduction for particular milling machine is done haphazardly. The food manipulation practices and food safety protocols were not followed by the operators because they did not know these procedures.

Since a high percentage of operators did not have basic education (66.7\% have junior secondary education, less or no education at all) the situation will remain the same until more operators get educated. It could even worsen if nothing is done to remedy 
the situation because most operators are young (90.5\% are 40 or below), male (95.1\%) and most of them own their milling machines.

Capacity building for the operators is a must and it should be carried out by the Accra Metropolitan Assembly (AMA) or any other stakeholders. A study conducted by Hanekom et al.[5] indicated the positive impact of training on safe food handling practices which can improve from $11.7 \%$ to $75 \%$ even two months after training.

The implementation of HACCP system is essential and particularly the GMP in order to produce hygienically acceptable products for human consumption [2, 3, 12, 15]. If not, consumers will be at high risk from micro-organisms especially the young, elderly and pregnant women [5, 14].

The results of this study could also serve as a warning for all other markets in the country to ensure safe food for all customers. This is true for rural markets where the degree of education is even lower than that of Accra. A follow up study is in progress where detailed HACCP will be recommended and action plan carried out especially in the area of capacity building and education of the operators. Then another audit will be carried out in order to evaluate the impact of the implementation but it will be interesting if the audit could be carried out by an independent team in order to avoid bias.

The selection of suitable metals for food industry used in the molding of the milling machines is crucial for the quality of the end-product. No scrap metals should be accepted in their production because their quality is questionable. The presence of heavy metals in the milled product is a threat to the consumers and even the operators.

\section{CONCLUSION}

Size reduction in Accra markets increases microbial contamination of the ground food commodities as seen in the study.

Due to the molding of the grinding parts using scrap metals whose origin and composition are unknown the milled food are contaminated with heavy metals. Lead was found in all the samples tested.

Some heavy metals constitute a serious health hazard for the consumer and the operator.

There is need for capacity building for operators in order to eliminate these threats. 


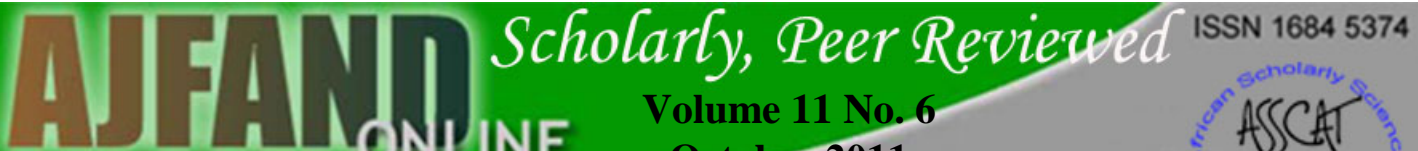 \\ DTIONLNE

Table 1: Marital status of operators in different markets

\begin{tabular}{|r|c|c|c|c|}
\hline \multicolumn{1}{|l|}{ Count } & \multicolumn{4}{|c|}{ Marital Status } \\
\hline \multicolumn{1}{|r|}{ Market area } & Single & Married & Widowed & Total \\
& & & & \\
& 3 & 6 & 0 & 9 \\
& Makola & 2 & 0 & 4 \\
Kantamanto & 2 & 4 & 1 & 8 \\
\hline Agbogbloshie & 3 & 12 & 1 & 21 \\
\hline
\end{tabular}

Table 2: Microbiological analysis of tomato samples $(n=36)$

\begin{tabular}{|l|l|l|l|l|l|l|l|l|}
\hline Sample & $\begin{array}{l}\text { Number } \\
\text { of } \\
\text { Dilutions }\end{array}$ & $\begin{array}{l}\mathrm{PCA}_{1} \\
\text { Average } \\
\text { counts } \\
\text { cfu/g }\end{array}$ & $\begin{array}{l}\mathrm{PCA}_{2} \\
\text { Average } \\
\text { counts } \\
\text { cfu/g }\end{array}$ & $\begin{array}{l}\mathrm{PCA}_{3} \\
\text { Average } \\
\text { counts } \\
\text { cfu/g }\end{array}$ & $\begin{array}{l}\text { Number } \\
\text { of } \\
\text { Dilutions } \\
\text { cfu/g }\end{array}$ & $\begin{array}{l}\mathrm{VRBG}_{1} \\
\text { Average } \\
\text { counts } \\
\text { cfu/g }\end{array}$ & $\begin{array}{l}\mathrm{VRBG}_{2} \\
\text { Average } \\
\text { counts } \\
\text { cfu/g }\end{array}$ & $\begin{array}{l}\text { VRBG } \\
\text { Average } \\
\text { counts } \\
\text { cfu/g }\end{array}$ \\
\hline $\mathrm{A}$ & $10^{-6}$ & 35 & 67 & 53 & $10^{-7}$ & 16 & 24 & 35 \\
\hline $\mathrm{A}^{1}$ & $10^{-8}$ & 230 & 215 & 195 & $10^{-7}$ & 77 & 25 & 32 \\
\hline $\mathrm{B}^{1}$ & $10^{-6}$ & 60 & 25 & 74 & $10^{-7}$ & 12 & 17 & 14 \\
\hline $\mathrm{C}$ & $10^{-8}$ & 343 & 100 & 226 & $10^{-7}$ & 66 & 42 & 38 \\
\hline $\mathrm{C}^{1}$ & $10^{-6}$ & 57 & 47 & 35 & $10^{-7}$ & 35 & 12 & 12 \\
\hline
\end{tabular}

A: sample A before milling in the different markets and $\mathrm{A}^{1}$ the same sample after milling

$\mathrm{B}$ : sample $\mathrm{B}$ before milling from different markets and $\mathrm{B}^{1}$ the same sample after milling

$\mathrm{C}$ : sample $\mathrm{C}$ before milling from different markets and $\mathrm{C}^{1}$ the same sample after milling. 


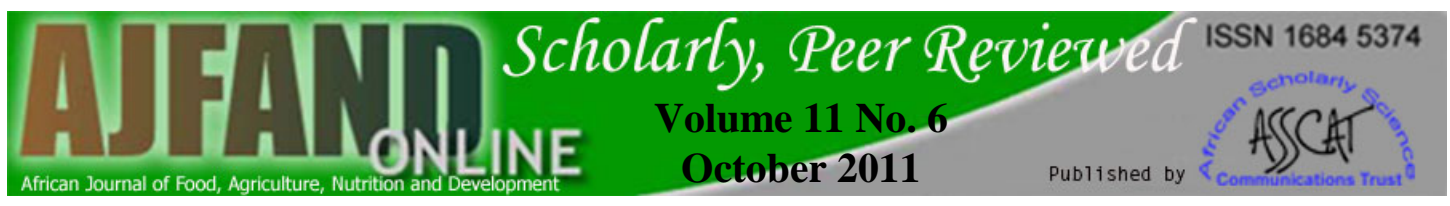

Table 3: Average content of heavy metals in ground foods in various markets

\begin{tabular}{|l|l|l|l|l|l|}
\hline Market & \multicolumn{5}{|l|}{ Heavy Metals in samples ppm } \\
\hline & Ni & Fe & $\begin{array}{l}\text { Pb } \\
\text { Max:0.3 }\end{array}$ & Zn & Mn \\
\hline Makola & 0.037 & 0.053 & 0.298 & 0.088 & 0.029 \\
\hline Nima & 0.040 & 0.054 & 0.280 & 0.103 & 0.053 \\
\hline Madina & 0.050 & 0.067 & 0.294 & 0.122 & 0.023 \\
\hline Average & 0.039 & 0.058 & 0.291 & 0.104 & 0.035 \\
\hline
\end{tabular}




\section{REFERENCES}

1. Brennan JG, Butters JR, Cowell ND and AEV Lilley Food Engineering Operations. 3rd Edition. Elsevier Science Publishers ltd. London; 1990.

2. Raspor $\mathbf{P}$ Total food chain safety: how good practices can contribute? Trends in Food Science \& Technology. 2008;19:405-412.

3. Sperber WH Future developments in food safety and HACCP. Food Control. 1998;9. No.2-3:129-130.

4. Sperber WH HACCP does not work from Farm to Table. Food Control. 2005; 16:511-514.

5. Hanekom SM, Vermeulen EE and W Oldewage-Theron Food safety Risk Factors in a Hospital Food Service unit serving low microbial diets to immunecompromised patients. African Journal of Food agriculture Nutrition and Development. AJFAND online2010;10 No9 September: 4000-4015.

6. Raspor $\mathbf{P}$ and $\mathbf{M}$ Jevsnik Good practice from producer to consumer. Crit. Rev. Food. Sci. Nutr. 2008; 48:276-292.

7. Gorman R, Bloomfield S and CC Adley A study of cross-contamination of food-borne pathogens in the domestic kitchen in the Republic of Ireland. International Journal of Food Microbiology.2002;76:143-150.

8. Barrie D The provision of food and catering services in hospitals. J. Hosp. Infec. 1996; 33:13-33.

9. Strohbehn C, Sneed J and SA Gilmore Food Safety Practices and Readiness to Implement HACCP programs in Assisted-Living Facilities in Iowa. J. Am. Diet. Assoc. 2004; 104:1678-1683.

10. Dehydrated Culture Media. http://www.oxoid.com/UK/blue.Accessed 06 December 2010.

11. Adu PK Undergraduate work. University of Ghana. 2009.

12. Mattick K, Durham K, Domingue G, Jorgensen F, Sen M, Schaffner DW and T Humphrey The survival of foodborne pathogens during domestic washing-up and subsequent transfer onto washing-up sponges, kitchen surfaces and food. International Journal of Food Microbiology.2002; 85:213-226.

13. Quaye W, Adofo K, Agyeman KO and F Nimoh Socioeconomic survey of traditional commercial Production of Cocoyam and Cocoyam leaf.African Journal of Food agriculture Nutrition and Development. AJFAND online 2010; 10 No 9 September: 4060-4078. 
14. Gerba $\mathbf{C} \mathbf{P}$, Rose JB and $\mathbf{C N}$ Haas Sensitive populations: who is at greatest risk? Int. J. Food. Microbiol. 1996; 30:113-123.

15. Kusumaningrum HD, Riboldi G, Hazeleger WC and RR Beumer Survival of Food borne pathogens on stainless steel surfaces and cross-contamination to Foods. International Journal of Food Microbiology. 2002; 85:227-238. 